\title{
Conversion of gas engine waste heat into cold using absorption chillers
}

\author{
Georgii Karman ${ }^{1}$, Yurii Oksen ${ }^{2, *}$, Olena Trofymova ${ }^{2}$, Yurii Komissarov ${ }^{2}$, Borys Dizhevskyi ${ }^{2}$, \\ Maksym Radiuk ${ }^{2}$, and Inna Diakun ${ }^{3}$ \\ ${ }^{1}$ General Electric, ST17 4UQ, Stafford, Lichfield Rd, 36, United Kingdom \\ ${ }^{2}$ Dnipro University of Technology, 49005, Dnipro, Yavornytskoho Ave., 19, Ukraine \\ ${ }^{3}$ Institute of Geotechnical Mechanics named by N. Poljakov of National Academy of Sciences of \\ Ukraine, 49005, Dnipro, Simferopolska Str., 2a, Ukraine
}

\begin{abstract}
A possibility of gas engine waste heat conversion into cold for air conditioning in mines using lithium bromide absorption chillers is investigated. Dependencies of parameters of a thermodynamic cycle and energy indicators of chillers on temperatures of a heating medium and a coolant are obtained using mathematical modelling. It is shown that it is rational to use two chillers with sequential movement of a heating medium and a coolant through them in opposite directions for a full conversion of gas engine waste heat. COP of such a system is 0.733 . This allows obtaining $2140 \mathrm{~kW}$ of cooling capacity with a coolant temperature of $7{ }^{\circ} \mathrm{C}$ when using a gas engine JMS- 620 by Jenbacher.
\end{abstract}

\section{Introduction}

Non-traditional energy-saving technologies [1 - 15] start to be applied more widely in coal mines of Ukraine at the present time. These technologies include heat pumps based on lowpotential heat and technologies of burning coal mine methane using gas engines (GE). GEs are cogeneration plants (modules) that generate electrical energy and waste heat for heating systems [1]. In some cases, large amounts of generated waste heat are "dumped" into the environment due to the lack of heat consumers. A possibility of converting this heat into additional electric energy is studied in the papers [13 - 15]. Excess waste heat of GEs can be converted into cold for air conditioning using lithium bromide absorption chillers (LBAC) in deep coal mines that require air conditioning of mine workings. The usage of LBAC instead of the traditionally used vapor-compression refrigeration systems significantly reduces consumption of electric energy and operating costs of generation of cold. There are known cases of generation of cold using LBAC in the world practice of air conditioning in mines, including those when waste heat from GEs is converted into cold [16].

The goal of this research is to determine thermal modes and energy efficiency of LBAC during utilization of GE waste heat and generation of cold for air conditioning in coal mines

*Corresponding author: oksenui49@gmail.com 
under the conditions of a specific scheme of LBAC and temperature modes of heating and cooled media.

\section{Methods}

GE JMS-620 by Jenbacher is currently used in Ukrainian mines. This module generates $3035 \mathrm{~kW}$ of electric energy and $2920 \mathrm{~kW}$ of thermal energy in a form of hot water from the engine cooling system. The water temperature varies from 110 to $70{ }^{\circ} \mathrm{C}$ as a result of heat loss. Consider a single-stage LBAC as a consumer of heat, the scheme of which is shown in Figure 1.

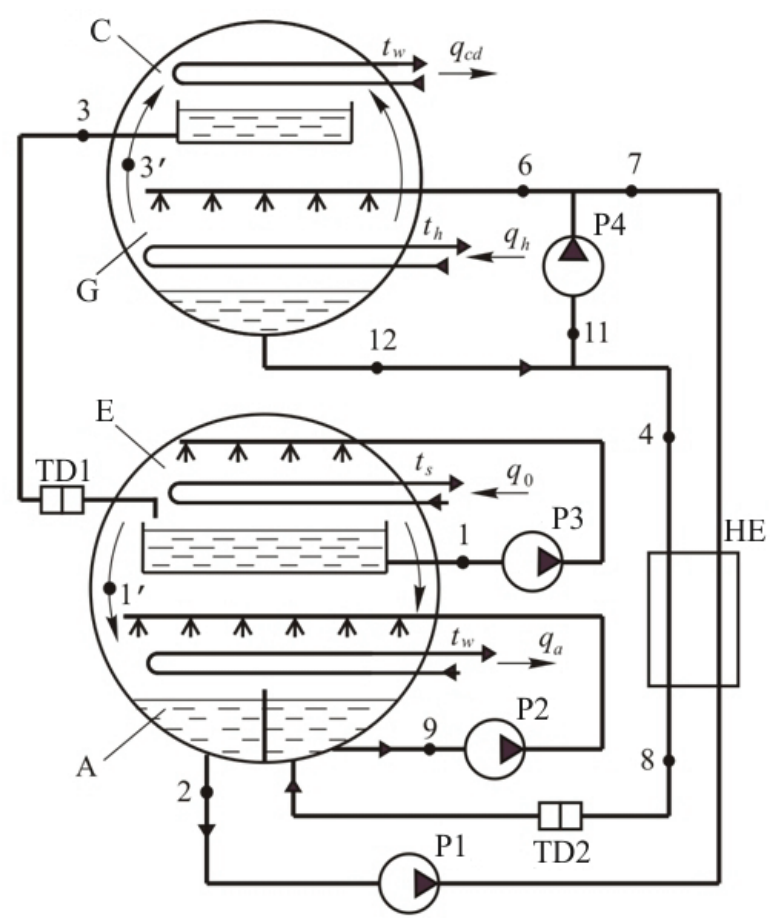

Fig. 1. Scheme of LBAC, where A - absorber, E- evaporator, G-generator, C - condenser, HE heat exchanger of solutions, P1, P2, P3, P4-pumps, TD1 and TD2-throttling devices; $t_{s}, t_{h}, t_{w},-$ temperatures of a coolant, heating and cooling media, ${ }^{\circ} \mathrm{C} ; q_{0}, q_{c d}, q_{a}, q_{h}-$ specific refrigerating capacity and specific thermal loads of a condenser, absorber, generator, $\mathrm{kJ} / \mathrm{kg}$. The numbers indicate characteristic points of flows of working media.

A refrigerant is water vapor and an absorbent is a water solution of lithium bromide $\mathrm{LiBr}$.

The liquid refrigerant is converted into steam in the evaporator $\mathrm{E}$ due to the specific refrigerating capacity $q_{0}$ supplied from an external source (coolant of the air conditioning system). The steam enters the absorber A and is absorbed by the water solution of LiBr. The specific thermal load of absorber $q_{a}$ is removed by cooling water. A weak solution (with a low concentration of $\mathrm{LiBr}$ ) is supplied to the generator G by the pump P1 through the heat exchanger of solutions HE. The weak solution is heated in the heat exchanger of solutions HE by the heat received from the strong solution (with a high concentration of $\mathrm{LiBr}$ ), which comes from the generator $\mathrm{G}$. The refrigerant is evaporated from the solution in the generator $\mathrm{G}$ due to the specific thermal load $q_{h}$ obtained from the heating medium (hot water from the GE cooling system) and is directed to the condenser C. Almost pure 
water vapor is evaporated in the generator $\mathrm{G}$ since the boiling points of water and lithium bromide are very different. The refrigerant vapor gives specific thermal load $q_{c d}$ to the cooling water and condenses in the condenser $\mathrm{C}$. The condensate is discharged into the evaporator $\mathrm{E}$ through the throttling device TD1. The strong solution of $\mathrm{LiBr}$ is discharged into the absorber A through the throttling device TD2 after passing through the heat exchanger of solutions HE.

The absorber $\mathrm{A}$ and the evaporator $\mathrm{E}$ are located in the lower drum, and the generator $\mathrm{G}$ and the condenser $\mathrm{C}$ are located in the upper drum. The absorber $\mathrm{A}$ and the generator $\mathrm{G}$ are film type devices. Their usage allows reducing thermodynamic losses from incomplete solution evaporation during the steam generation and incomplete solution saturation during the absorption compared to the flooded devices. The scheme provides recirculation of solutions and a refrigerant by using pumps P2, P3 and P4 in order to intensify the heat and mass transfer processes.

The operating process of LBAC is graphically represented in Figure 2 in $h, \xi-$ coordinates ( $h$ is enthalpy, $\mathrm{kJ} / \mathrm{kg}$, $\xi$ is mass concentration of lithium bromide in a solution, $\%$ ). The cycle of solution state change $2-7-6-5-4-8-9-10-2$ is shown on the background of isobars $p_{a}$ and $p_{h}$ of a saturated liquid. Isobars of the superheated water vapor, which is in equilibrium with the saturated solution of $\mathrm{LiBr}$, are shown in the upper part of the figure. The numbers of characteristic points of the process correspond to the numbers of points shown in the scheme of LBAC (Fig. 1).

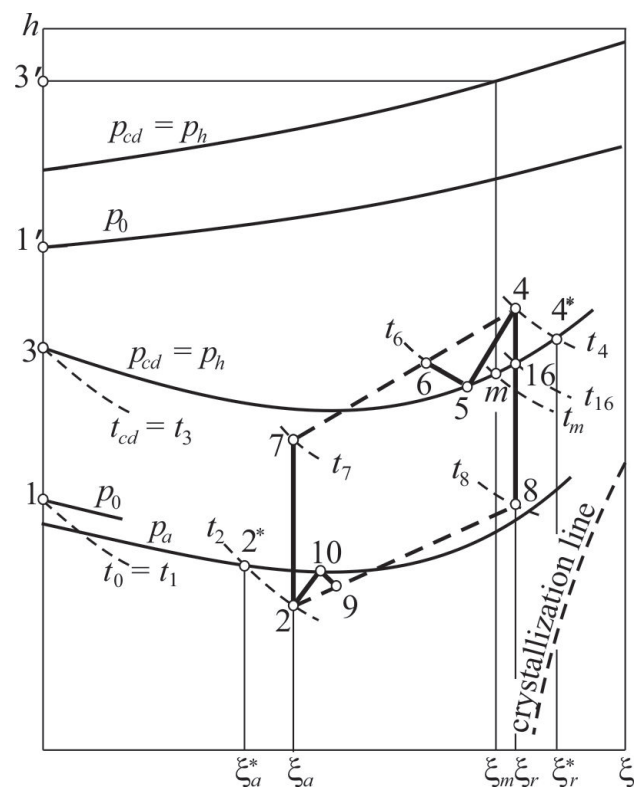

Fig. 2. Scheme of operating process of LBAC, where $p_{h}, p_{c d}, p_{0}, p_{a}$ are pressures in generator $\mathrm{G}$, condenser $\mathrm{C}$, evaporator $\mathrm{E}$, and absorber A, respectively, $\mathrm{Pa} ; \xi_{a}, \xi_{r}$ and $\xi_{a}^{*}, \xi_{r}^{*}$ are concentrations of $\mathrm{LiBr}$ in weak and strong solution for real and theoretical cycle, respectively, \%; $\xi_{m}$ is concentration of $\mathrm{LiBr}$ in solution with parameters of state at point $m, \% ; t_{1}-t_{16}, t_{m}$ are solution temperatures at characteristic points of process, ${ }^{\circ} \mathrm{C} ; t_{0}, t_{c d}$ are boiling and condensation points, respectively, ${ }^{\circ} \mathrm{C}$.

During the analyzing of operating process assume that:

- pressures in the operating space of the generator $\mathrm{G}$ and condenser $\mathrm{C}$ blocks are equal

$$
p_{h}=p_{c d}
$$

- pressure $p_{0}$ in the evaporator E exceeds pressure $p_{a}$ in the absorber A by the amount of 
hydraulic losses

$$
\Delta p_{a}=p_{0}-p_{a}
$$

- concentration of the weak solution at the absorber A outlet (at point 2) $\xi_{a}$ differs from the equilibrium one $\xi_{a}^{*}$ for a temperature $t_{2}$ at point 2 by the amount of incompleteness of saturation

$$
\Delta \xi_{a}=\xi_{a}-\xi_{a}^{*}
$$

- concentration of the strong solution at the generator $G$ outlet (at point 4) $\xi_{r}$ differs from the equilibrium one $\xi_{r}^{*}$ for a temperature $t_{4}$ at point 4 by the amount of incompleteness of evaporation

$$
\Delta \xi_{r}=\xi_{r}^{*}-\xi_{r}
$$

Lines $2-7$ and $4-8$ in Figure 2 correspond to processes of heating the weak and cooling the strong solution in the heat exchanger of solutions HE. Point 6, which determines the state of solution before the generator G nozzles, is located on a line $7-4$ of mixing of solutions with parameters of states at points 7 and 4. Similarly, point 9 is located on a line $8-2$ of mixing of solutions with parameters of states at points 8 and 2 . The solution is superheated at point 6 compared to a saturation state at temperature $t_{6}$ and pressure $p_{h}$ in the generator $\mathrm{G}$. The solution is supercooled at point 9 compared to a saturation state at temperature $t_{9}$ and pressure $p_{a}$ in the absorber A. Processes $6-5$ and 9 - 10 are considered isobaric-adiabatic. The refrigerant is evaporated during process $6-5$ due to reduction of the solution enthalpy. Further evaporation of the refrigerant occurs during process $5-4$ due to the supply of heat from the heating medium. The solution superheats in this case and the resulting refrigerant vapor is in a state of equilibrium with a saturated solution. The state of saturated solution changes along line $5-16$. Assume that the temperature of formed refrigerant vapor is equal to the average solution temperature $t_{m}$ on line $5-16$

$$
t_{m}=\left(t_{5}+t_{16}\right) / 2
$$

The refrigerant vapor state at the generator $\mathrm{G}$ outlet (condenser inlet) is determined by point $3^{\prime}$, at the condenser $\mathrm{C}$ outlet - by point 3 , at the evaporator $\mathrm{E}$ outlet - by point $1^{\prime}$ in the scheme. All these points are located on the vertical $\xi=0$.

The initial data for calculating the parameters and constructing the cycle are:

$t_{s 2}$ is final temperature of cooled coolant, ${ }^{\circ} \mathrm{C}$;

$t_{h 2}$ is final temperature of heating medium, ${ }^{\circ} \mathrm{C}$;

$t_{w}$ is final temperature of cooling water, ${ }^{\circ} \mathrm{C}$;

$\Delta t_{2-8}$ is temperature difference at a cold end of a heat exchanger of solutions $\mathrm{HE},{ }^{\circ} \mathrm{C}$;

$\Delta t_{a}, \Delta t_{g}, \Delta t_{e v}$ and $\Delta t_{c d}$ are minimum temperature differences in absorber $\mathrm{A}$, generator $\mathrm{G}$, evaporator $\mathrm{E}$ and condenser $\mathrm{C},{ }^{\circ} \mathrm{C}$;

$\Delta p_{a}$ are refrigerant vapor pressure losses during movement from evaporator $\mathrm{E}$ to absorber $\mathrm{A}, \mathrm{Pa}$;

$\Delta \xi_{a}$ is incompleteness of saturation of solution in absorber $\mathrm{A}, \%$;

$\Delta \xi_{r}$ is incompleteness of evaporation of refrigerant in generator $\mathrm{G}, \%$;

$\alpha_{g}$ is coefficient of recirculation of solution in generator $\mathrm{G}$, which is a ratio of mass flow rates of strong solution $m$ at points 11 and 4 (Fig. 1):

$$
\alpha_{g}=m_{11} / m_{4} \text {. }
$$


Calculation of parameters at the characteristic points of the cycle is performed in the following way.

Temperature of the weak $t_{2}$ and strong $t_{4}$ solutions at the absorber and generator outlet (at points 2 and 4, respectively) is determined. The boiling $t_{0}$ and condensation $t_{c d}$ points of the refrigerant at the evaporator $\mathrm{E}$ and the condenser $\mathrm{C}$ outlet (at points 1 and 3 , respectively), and the temperature $t_{8}$ of the strong solution at the outlet of heat exchanger of solutions (at point 8) are determined:

$$
\begin{aligned}
& t_{2}=t_{W}+\Delta t_{a}, \\
& t_{4}=t_{h}-\Delta t_{g}, \\
& t_{0}=t_{1}=t_{s}-\Delta t_{e v}, \\
& t_{c d}=t_{3}=t_{W}+\Delta t_{c d}, \\
& t_{8}=t_{2}+\Delta t_{2-8} .
\end{aligned}
$$

The saturated water vapor pressure in the evaporator $\mathrm{E} p_{0}$ and in the condenser $\mathrm{C} p_{c d}$ are determined using the temperatures $t_{0}$ and $t_{c d}$. The pressure in the generator $\mathrm{G} p_{h}$ and the absorber A $p_{a}$. is determined using the formulas (1) and (2).

Concentration of the weak solution $\xi_{a}{ }^{*}$ is determined from the pressure $p_{0}$ and the temperature $t_{2}$, concentration of the strong solution $\xi_{r}{ }^{*}-$ from the pressure $p_{h}$ and the temperature $t_{4}$ (for the theoretical cycle - when losses from incomplete saturation of the solution in the absorber $A$ and incomplete evaporation in the generator $G$ are absent). Concentration of the weak $\xi_{a}$ and strong $\xi_{r}$ solution for the real cycle is determined using the formulas (3) and (4). After that, the location of points 2, 4, 8 and the solution enthalpy in these points are determined using temperatures and concentrations.

Enthalpy of the heated weak solution (at point 7) is calculated using the heat balance equation of the heat exchanger of solutions $\mathrm{HE}$

$$
q_{h e}=(f-1)\left(h_{4}-h_{8}\right)=f\left(h_{7}-h_{2}\right),
$$

where $q_{h e}$ is heat flow in heat exchanger, $\mathrm{kJ} / \mathrm{kg} ; h_{4}, h_{8}, h_{7}, h_{2}$ is solution enthalpy determined at points $4,8,7,2, \mathrm{~kJ} / \mathrm{kg}$; $f$ is circulation ratio, determined using formula

$$
f=\frac{m_{a}}{m_{v}}=\frac{m_{7}}{m_{3}}=\frac{\xi_{r}}{\xi_{r}-\xi_{a}}=\frac{\xi_{r}}{\Delta \xi},
$$

where $m_{a}$ and $m_{v}$ are mass flow rates of the weak solution of $\mathrm{LiBr}$ entering the generator $\mathrm{G}$ and water vapor leaving the generator $\mathrm{G}, \mathrm{kg} / \mathrm{s} ; m_{3}=m_{v}$ and $m_{7}=m_{a}$ are mass flow rates of media at points 3 and 7 of the scheme of LBAC, kg/s (Fig. 1).

Parameter $\Delta \xi=\xi_{r}-\xi_{a}$ in formula (13) is the solution degassing zone, $\%$. The enthalpy and concentration of $\mathrm{LiBr}$ of the resulting flow (at point 6 ) is calculated using the equations of heat balance and material balance for $\mathrm{LiBr}$ salt for the mixing point of flows with parameters of points 7 and 11:

$$
h_{6}=\frac{m_{11} h_{11}+m_{7} h_{7}}{m_{6}}=\frac{\alpha_{g}(f-1) h_{4}+f h_{7}}{\alpha_{g}(f-1)+f},
$$




$$
\xi_{6}=\frac{m_{11} \xi_{11}+m_{7} \xi_{7}}{m_{6}}=\frac{\alpha_{g}(f-1) \xi_{4}+f \xi_{7}}{\alpha_{g}(f-1)+f}
$$

where $m_{6}$ and $m_{11}$ are mass flow rates of solution at points 6 and 11 of scheme of LBAC, $\mathrm{kg} / \mathrm{s} ; h_{11}$ is enthalpy of solution at point $11, \mathrm{~kJ} / \mathrm{kg} ; \xi_{4}, \xi_{7}, \xi_{11}$ are mass concentrations of $\mathrm{LiBr}$ in solution at points $4,7,11, \%$.

Balance equations are characteristic for the isobaric-adiabatic process 6 - 5 of separation of the superheated solution into the saturated solution with parameters of state at point 5 and the superheated water vapor, which is in equilibrium with a saturated solution:

$$
\begin{aligned}
& m_{6}=m_{5}+m_{v 5}, \\
& m_{6} h_{6}=m_{5} h_{5}+m_{r 5} h_{v 5}, \\
& m_{6} \xi_{6}=m_{5} \xi_{5},
\end{aligned}
$$

where $h_{v 5}$ and $m_{v 5}$ are enthalpy of water vapor $(\mathrm{kJ} / \mathrm{kg})$ formed in process $6-5$, and water vapor mass flow rate $(\mathrm{kg} / \mathrm{s}) ; m_{5}$ is mass flow rate of solution at point 5 of scheme of LBAC, $\mathrm{kg} / \mathrm{s} ; h_{5}$ and $h_{6}$ are enthalpies of solution at points 5 and $6, \mathrm{~kJ} / \mathrm{kg} ; \xi_{5}$ and $\xi_{6}$ are mass concentration of $\mathrm{LiBr}$ in solution at points 5 and $6, \%$.

Then the concentration of $\mathrm{LiBr}$, the saturated solution enthalpy at point 5 of the cycle, the parameters of the water vapor, which is in equilibrium with a saturated solution, and the mass flow rates $m_{5}$ and $m_{v 5}$ are calculated using equations (16) - (18). This is performed considering the dependencies of enthalpy of saturated solution and of superheated water vapor, which is in equilibrium with a saturated solution, depending on the temperature and concentration of $\mathrm{LiBr}$.

The water vapor enthalpy $h_{3^{\prime}}$, which is formed as a result of the solution boiling during process $5-4$ is determined using the concentration $\xi_{m}$ and the pressure $p_{h}$. The enthalpy of saturated water vapor $h_{1}$, at the evaporator E outlet (at point 1) is determined using the temperature $t_{0}$.

Calculation of thermodynamic parameters of the solution of $\mathrm{LiBr}$ and water vapor are calculated using the formulas given in papers $[17,18]$.

Energy characteristics of the cycle are calculated after determining the parameters at the characteristic points of the cycle: specific refrigerating capacity $q_{0}$, specific thermal loads of condenser $\mathrm{C} q_{c d}$, absorber A $q_{a}$, generator $\mathrm{G} q_{h}(\mathrm{~kJ} / \mathrm{kg})$ and coefficient of performance (COP):

$$
\begin{aligned}
& q_{0}=h_{1^{\prime}}-h_{3}, \\
& q_{c d}=h_{3^{\prime}}-h_{3}, \\
& q_{a}=h_{1^{\prime}}+f\left(h_{8}-h_{2}\right)-h_{8}, \\
& q_{h}=h_{3^{\prime}}+f\left(h_{4}-h_{7}\right)-h_{4}, \\
& \operatorname{COP}=\frac{q_{0}}{q_{h}} .
\end{aligned}
$$

COP indicates how much cold can be obtained in the evaporator E during consumption of a unit of heat in the generator $\mathrm{G}$.

The following limitations are applied to the parameters of cycles of LBACs. The mass 
concentration $\xi_{r}$ of the strong solution of $\mathrm{LiBr}$ must not exceed $64 \%$ due to the danger of crystallization [19], and the solution degassing zone $\Delta \xi$ should be in a range of 3.5 to $4.5 \%$ [20], according to the rational hydraulic conditions of the absorber $\mathrm{A}$ and the generator $\mathrm{G}$.

\section{Results and discussion}

The specific refrigerating capacity $q_{0}$ produced by LBAC depends on the amount of specific thermal load $q_{h}$ and the chiller COP as shown in the formula (23). These values depend on external conditions, i.e., on the temperatures of heating medium $t_{h}$ and the coolant $t_{s}$. The temperature $t_{h}$ of heating medium (water from the GE cooling system) can vary from $t_{h 1}=110^{\circ} \mathrm{C}$ to $t_{h 2}=70^{\circ} \mathrm{C}$. The coolant of air conditioning systems is cooled in chillers by $10 \ldots 12{ }^{\circ} \mathrm{C}[21-23]$. Therefore, the boundaries of changes of temperature range can be assumed equal to $t_{s 1}=17^{\circ} \mathrm{C}$ and $t_{s 2}=7^{\circ} \mathrm{C}$.

Calculations are performed according to the method described above in order to establish the influence of temperatures of heating and cooled media on a thermal mode and LBAC efficiency.

The following parameters are assumed for calculations:

- final temperature of the water cooling the condenser $\mathrm{C}$ and the absorber $\mathrm{A}, t_{w}=26{ }^{\circ} \mathrm{C}$;

- temperature difference at the cold end of the heat exchanger of solutions $\mathrm{HE}$ $\Delta t_{2-8}=15^{\circ} \mathrm{C}$;

- minimum temperature difference in the absorber $\mathrm{A}$, generator $\mathrm{G}$, evaporator $\mathrm{E}$ and the condenser $\mathrm{C}$, respectively $\Delta t_{a}=6{ }^{\circ} \mathrm{C}, \Delta t_{g}=5{ }^{\circ} \mathrm{C}, \Delta t_{e v}=3{ }^{\circ} \mathrm{C}$ and $\Delta t_{c d}=4{ }^{\circ} \mathrm{C}$;

- refrigerant vapor pressure losses during movement from the evaporator $\mathrm{E}$ to the absorber A $\Delta p_{a}=0.13 \mathrm{kPa}$;

- incompleteness of saturation of the solution in the absorber A $\Delta \xi_{a}=0.5 \%$;

- incompleteness of evaporation of the refrigerant in the generator $\mathrm{G} \Delta \xi_{r}=1.5 \%$;

- coefficient of recirculation of the solution in the generator $\mathrm{G} \alpha_{g}=3.0$.

The main calculation results are given in table 1. Graphs of COP dependencies on final temperatures of heating and cooled medium are built in Fig. 3 and 4.

Table 1. Calculation results of thermal modes of LBAC.

\begin{tabular}{|c|c|c|c|c|c|c|c|c|c|c|c|}
\hline Mode & $\begin{array}{c}t_{h}, \\
{ }^{\circ} \mathrm{C}\end{array}$ & $\begin{array}{c}t_{s}, \\
{ }^{\circ} \mathrm{C}\end{array}$ & $\begin{array}{c}\xi_{a}, \\
\%\end{array}$ & $\begin{array}{c}\xi_{r}, \\
\%\end{array}$ & $f$ & $\begin{array}{c}q_{h}, \\
\mathrm{~kJ} / \mathrm{kg}\end{array}$ & $\begin{array}{c}q_{a}, \\
\mathrm{~kJ} / \mathrm{kg}\end{array}$ & $\begin{array}{c}q_{c d}, \\
\mathrm{~kJ} / \mathrm{kg}\end{array}$ & $\begin{array}{c}q_{0}, \\
\mathrm{~kJ} / \mathrm{kg}\end{array}$ & $\eta$ & $\begin{array}{c}\Delta \xi, \\
\%\end{array}$ \\
\hline 1 & 79.0 & 7.00 & 56.22 & 58.74 & 23.26 & 3466.3 & 3343.1 & 2505.9 & 2382.6 & 0.687 & 2.526 \\
\hline 2 & 80.0 & 7.00 & 56.22 & 59.20 & 19.88 & 3369.7 & 3244.9 & 2507.5 & 2382.6 & 0.707 & 2.977 \\
\hline 3 & 81.0 & 7.00 & 56.22 & 59.65 & 17.39 & 3300.2 & 3173.7 & 2509.1 & 2382.6 & 0.722 & 3.429 \\
\hline 4 & 82.0 & 7.00 & 56.22 & 60.09 & 15.51 & 3248.9 & 3120.8 & 2510.7 & 2382.6 & 0.733 & 3.875 \\
\hline 5 & 83.0 & 7.00 & 56.22 & 60.53 & 14.03 & 3209.8 & 3080.2 & 2512.3 & 2382.6 & 0.742 & 4.314 \\
\hline 6 & 84.0 & 7.00 & 56.22 & 60.97 & 12.83 & 3179.0 & 3047.7 & 2513.9 & 2382.6 & 0.750 & 4.754 \\
\hline 7 & 86.0 & 7.00 & 56.22 & 61.84 & 11.00 & 3134.7 & 3000.3 & 2517.0 & 2382.6 & 0.760 & 5.620 \\
\hline 8 & 90.0 & 7.00 & 56.22 & 63.53 & 8.69 & 3085.1 & 2944.4 & 2523.3 & 2382.6 & 0.772 & 7.311 \\
\hline 9 & 91.0 & 7.00 & 56.22 & 63.95 & 8.27 & 3077.2 & 2935.0 & 2524.9 & 2382.6 & 0.774 & 7.732 \\
\hline 10 & 70.0 & 13.00 & 51.87 & 54.46 & 21.05 & 3318.8 & 3222.8 & 2489.6 & 2393.6 & 0.721 & 2.587 \\
\hline 11 & 70.0 & 13.50 & 51.49 & 54.46 & 18.37 & 3230.3 & 3135.5 & 2489.4 & 2394.5 & 0.741 & 2.965 \\
\hline 12 & 70.0 & 14.00 & 51.13 & 54.46 & 16.35 & 3162.9 & 3069.1 & 2489.2 & 2395.4 & 0.757 & 3.331 \\
\hline 13 & 70.0 & 14.50 & 50.75 & 54.46 & 14.68 & 3106.3 & 3013.6 & 2489.0 & 2396.4 & 0.771 & 3.710 \\
\hline 14 & 70.0 & 15.00 & 50.37 & 54.46 & 13.32 & 3059.3 & 2967.8 & 2488.9 & 2397.3 & 0.784 & 4.088 \\
\hline 15 & 70.0 & 15.50 & 49.98 & 54.46 & 12.16 & 3018.5 & 2928.0 & 2488.7 & 2398.2 & 0.795 & 4.479 \\
\hline
\end{tabular}

COP, width of the degassing zone $\Delta \xi$, and the concentration of the strong solution $\xi_{r}$ increase during increase of temperatures $t_{h}$ and $t_{s}$, as shown in Table 1, Figure 3, and 
Figure 4 . The concentration of the strong solution $\xi_{r}$ reaches the $64 \%$ boundary value from the condition of solution crystallization at $t_{h}=91{ }^{\circ} \mathrm{C}$ (calculation mode 9 , Table 1 ). A decrease of $t_{h}$ leads to narrowing of the degassing zone, which at $81{ }^{\circ} \mathrm{C}$ (mode 3 ) becomes equal to the lower boundary of the $3.5 \ldots 4.5 \%$ range recommended in the paper [20].

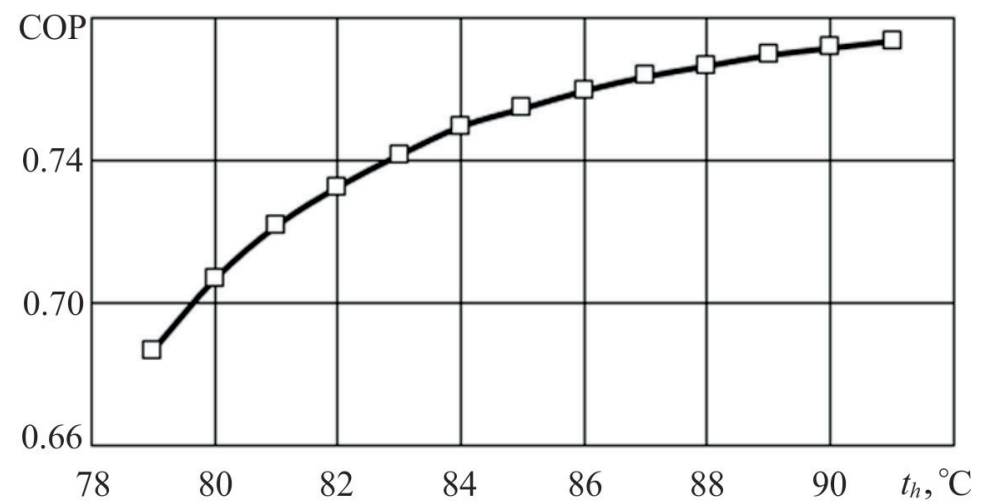

Fig. 3. Dependency of COP on temperature of heating medium at $t_{s}=7^{\circ} \mathrm{C}$.

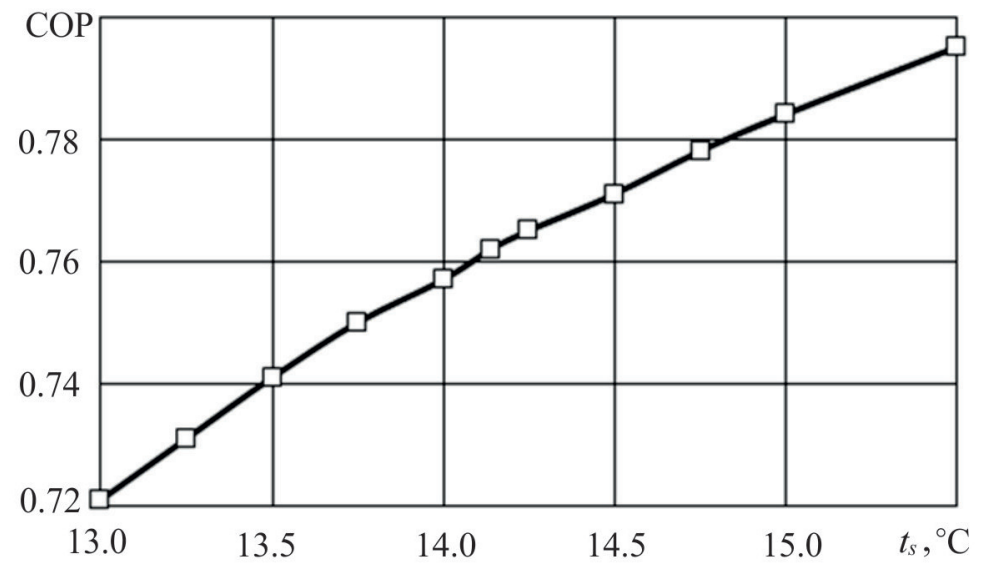

Fig. 4. Dependency of COP on temperature of cooled coolant at $t_{h}=70^{\circ} \mathrm{C}$.

Thus, the results indicate that the operating range of final temperatures of the heating medium (from $80{ }^{\circ} \mathrm{C}$ to $84{ }^{\circ} \mathrm{C}$ ) is significantly limited. It is impossible to utilize all the GE waste heat in one LBAC, while reducing its potential to $70^{\circ} \mathrm{C}$ and cooling the coolant to $7^{\circ} \mathrm{C}$. The analysis also shows that the increase of final coolant temperature allows reducing the heating medium temperature (modes $10-15$ ), and the solution degassing zone widens as well.

The scheme of simultaneous operation of two LBACs with the sequential movement of the heating and cooled media through them is suggested (Fig. 5) considering the character of change of parameters of the LBAC cycle. This is aimed at increasing the completeness of GE waste heat conversion and, accordingly, the completeness of cooling the coolant for air conditioning systems.

The heating medium first enters LBAC number 1 with a high-temperature generator and a low-temperature evaporator, and then flows to LBAC number 2 with a low-temperature generator and a high-temperature evaporator, as shown in Figure 5. The coolant is first cooled in the evaporator of LBAC number 2, and then the final cooling occurs in the 
evaporator of LBAC number 1.

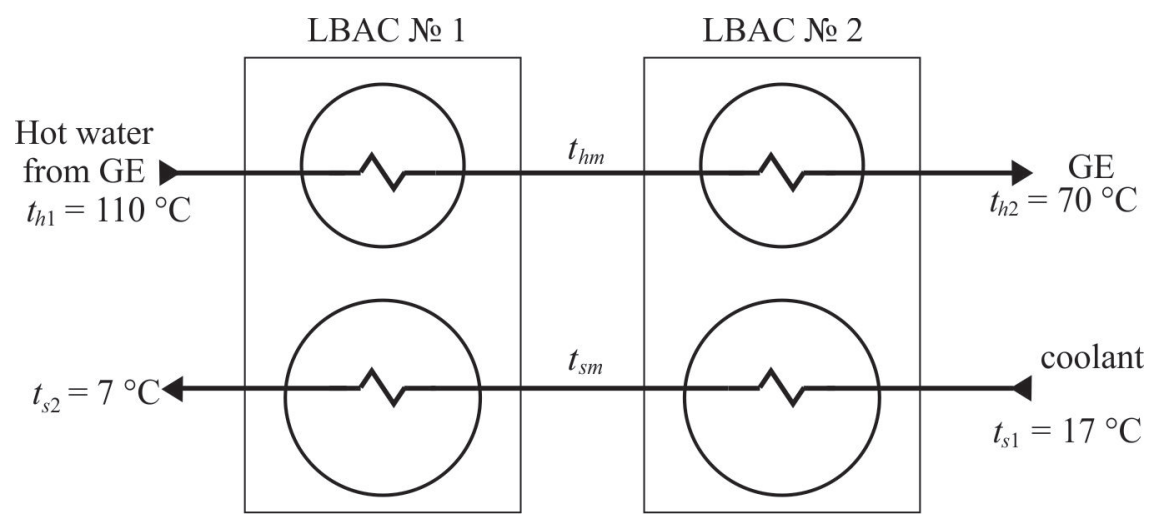

Fig. 5. Scheme of GE waste heat utilization using a system of two LBACs, where $t_{h m}$ and $t_{s m}$ are intermediate temperatures (after the first cooling stage) of heating medium and coolant, ${ }^{\circ} \mathrm{C}$.

A method of calculation of thermal modes of such a system is developed. The main calculation results are shown in Table. 2.

Table 2. Calculation results of thermal modes of a system of two LBACs.

\begin{tabular}{|c|c|c|c|c|c|c|c|c|c|c|c|c|}
\hline $\begin{array}{c}t_{h m}, \\
{ }^{\circ} \mathrm{C}\end{array}$ & $\begin{array}{c}t_{s m}, \\
{ }^{\circ} \mathrm{C}\end{array}$ & $\begin{array}{c}\xi_{a 1}, \\
\%\end{array}$ & $\begin{array}{c}\xi_{r 1}, \\
\%\end{array}$ & $\begin{array}{c}\xi_{a 2}, \\
\%\end{array}$ & $\begin{array}{c}\xi_{r 2}, \\
\%\end{array}$ & $\begin{array}{c}\Delta \xi_{1}, \\
\%\end{array}$ & $\begin{array}{c}\Delta \xi_{2}, \\
\%\end{array}$ & $b_{h 1}$ & $b_{s 1}$ & $\eta_{1}$ & $\eta_{2}$ & $\eta$ \\
\hline 79.0 & 14.54 & 56.2 & 58.7 & 50.7 & 54.5 & 2.53 & 3.73 & 0.775 & 0.754 & 0.687 & 0.772 & 0.707 \\
\hline 80.0 & 14.34 & 56.2 & 59.2 & 50.9 & 54.5 & 2.98 & 3.59 & 0.750 & 0.734 & 0.707 & 0.767 & 0.722 \\
\hline 81.0 & 14.14 & 56.2 & 59.7 & 51.0 & 54.5 & 3.43 & 3.44 & 0.725 & 0.714 & 0.722 & 0.762 & 0.733 \\
\hline 82.0 & 13.94 & 56.2 & 60.1 & 51.2 & 54.5 & 3.87 & 3.28 & 0.700 & 0.694 & 0.733 & 0.755 & 0.740 \\
\hline 83.0 & 13.73 & 56.2 & 60.5 & 51.3 & 54.5 & 4.31 & 3.14 & 0.675 & 0.673 & 0.742 & 0.749 & 0.745 \\
\hline
\end{tabular}

Parameters shown in Table 2 are:

$t_{h m}$ and $t_{s m}$ are intermediate temperatures (after the first stage of cooling) of the heating medium and coolant, ${ }^{\circ} \mathrm{C}$;

$\xi_{a 1}, \xi_{r 1}, \xi_{a 2}, \xi_{r 2}$ are concentrations of weak and strong solutions of $\mathrm{LiBr}$ in LBAC number 1 and 2 , respectively, $\%$;

$\Delta \xi_{1}$ and $\Delta \xi_{2}$ are solution degassing zones in LBAC number 1 and 2, \%;

$\eta_{1}, \eta_{2}$ and $\eta$ are COP in LBAC number 1,2 and in the entire system;

$b_{h 1}$ and $b_{s 1}$ are partial involvement of LBAC number 1 in lowering the temperature of heating and cooled media:

$$
\begin{aligned}
& b_{h 1}=\frac{t_{h 1}-t_{h m}}{t_{h 1}-t_{h 2}}, \\
& b_{s 1}=\frac{t_{s m}-t_{s 2}}{t_{s 1}-t_{s 2}} .
\end{aligned}
$$

Analysis of the results shows that the degassing zone of LBAC number 1 widens, and the degassing zone of LBAC number 2 narrows during increase of the intermediate temperature of heating medium $t_{h m}$. Degassing zones of both machines become identical at $t_{h m}=81{ }^{\circ} \mathrm{C}$ and almost equal to the lower boundary $(3.5 \%)$ of the recommended range of values in the papers of other authors. LBAC number 1 utilizes $72.5 \%$ of all available heat and provides a decrease of the waste coolant temperature by $71.4 \%$ in this mode. COPs of 
LBAC number 1,2 and the entire system are $0.722,0.762$ and 0.733 , respectively.

The cooling capacity of GE JMS-620 is $2920 \mathrm{~kW}$ [1]. In this case, the cooling capacity generated by a system of two LBACs at COP of 0.733 is $2140 \mathrm{~kW}$.

\section{Conclusions}

Dependencies of COP of heat into cold conversion and solution degassing zones on temperatures of heating and cooled media are established on a basis of mathematical modelling of thermal modes of a single-stage LBAC with a film generator, absorber and recirculation of solution of $\mathrm{LiBr}$. A scheme of a system of two LBACs operating under different temperature modes is suggested. This allows fully utilizing GE JMS-620 waste heat, reducing its heat potential from 110 to $70{ }^{\circ} \mathrm{C}$, and providing necessary temperature reduction of a coolant for an air conditioning systems from 17 to $7^{\circ} \mathrm{C}$. COP of heat into cold conversion of a system is 0.733 . Research results evidence a potential of practical implementation of a suggested technical solution.

\section{References}

1. Fedorov, S.D., Oblakevich, S.V., Radiuk, O.P. (2006). The problem of utilization coal mine methane in cogeneration plants and ways to solve it on the example of the mine name by A.F. Zasiadko. Promelectro, 5, 35-39

2. Semenenko, Ye.V., Diakun, I.L., Ruban, V.D. (2013). Prospects for the creation and implementation of energy complexes at coal mining enterprises. Ugol Ukrainy, 7, 30-34

3. Semenenko Ye.V., Diakun I.L. (2014) Economic prospects for coal methane utilization. In: Prospects for the use of alternative and renewable energy sources in Ukraine, 2 , 304-310

4. Voloshyn, O., Potapchuk, I., Yemelianenko, V., Zhovtonoha, M., Pertsevyi, V. (2019). Experimental study for the process of the borehole thermal reaming by means of the angular plasmatron. In: E3S Web of Conferences, International Conference Essays of Mining Science and Practice, 109, https://doi.org/10.1051/e3sconf/201910900113

5. Voloshyn, O.I., Potapchuk, I.Y., Zhevzhyk, O.V. (2018). Influence of the heat-transfer stream pressure on the surface of the rock in a process of the thermal reaming of the borehole. Naukovyi Visnyk Natsionalnoho Hirnychoho Universytetu, (2), 53-59

6. Kyrychenko, Y., Samusia, V., Kyrychenko, V., Romanyukov, A. (2013). Experimental investigation of aero-hydroelastic instability parameters of the deep-water hydrohoist pipeline. Middle-East Journal of Scientific Research, 18 (4), 530-534

7. Kyrychenko, E., Samusya, V., Kyrychenko, V., Antonenko, A. (2015). Thermodynamics of multiphase flows in relation to the calculation of deep-water hydraulic hoisting In: New Developments in Mining Engineering: Theoretical and Practical Solutions of Mineral Resources Mining, 305-311

8. Ilin, S.R., Samusya, V.I., Kolosov, D.L., Ilina, I.S., Ilina, S.S. (2018). Risk-forming dynamic processes in units of mine hoists of vertical shafts. Naukovyi Visnyk Natsionalnoho Hirnychoho Universitetu, (5), 64-71

9. Pivnyak, G., Samusia, V., Oksen, Y., Radiuk, M. (2014). Parameters optimization of heat pump units in mining enterprises. In: Progressive technologies of coal, coalbed methane and ores mining, 19-24

10. Oksen, Y., Samusia, O. (2014). Economic efficiency of heat pump technology for geothermal heat recovery from mine water. In: Progressive technologies of coal, coalbed methane, and ores mining, 191-194

11. Pivnyak, G., Samusia, V., Oksen, Y., Radiuk, M. (2015). Efficiency increase of heat pump 
technology for waste heat recovery in coal mines. In: New Developments in Mining Engineering: Theoretical and Practical Solutions of Mineral Resources Mining, 1-4

12. Oksen, Y., Radiuk, M., Komissarov, Y., Kirsanov, M. (2019). Energy efficiency of cogeneration utilization of residual heat of flue gases during the drying of coal concentrate in pipe-dryers. In: E3S Web of Conferences, International Conference Essays of Mining Science and Practice, 109, https://doi.org/10.1051/e3sconf/ 201910900065

13. Oksen, Yu.I., and Radiuk, M.V. (2009). Investigation effectiveness of the use of waste heat gas piston installations for electricity generation, Geotekhnicheskaya Mekhanika [Geo-technical Mechanics], 81, 200-207

14. Oksen, Yu.I., Trofymova, E.P, Pisarev, V.P. (2019). Study of the efficiency of conversion of waste heat of gas reciprocating plants to electrical energy. Hirnycha elektromekhanika ta avtomatyka, 101, 104-109

15. Oksen, Yu.I., Trofymova, O., Bobryshov, O., Lukisha, A., Pryvalov, V. (2019). Gas engines waste heat recovery to electrical energy. In: E3S Web of Conferences, International Conference Essays of Mining Science and Practice, 109, https://doi.org/10.1051/e3sconf/201910900066

16. Barteczko, B., Nawrat, S., Rzepski, H., Schöler, J. (2001). Wytwarzanie w skojarzeniu prądu elektrycznego, ciepła i chłodu na potrzeby podziemnej klimatyzacji KWK "Pniówek". Ciepłownictwo, Ogrzewnictwo, Wentylacja, 32 (10), 22-27

17. Forrest S. Yount (2017) Fundamentals Volume Subcommittee (ASHRAE HANDBOOK COMMITTEE)

18. Baranenko, A.V., Tymofeevskyi, L.S., Dolotov, A.H., Popov, A.V. (2005). Absorbtsionnyye preobrazovateli teploty. Sankt-Peterburg: SPbGUNiPT

19. Galymova, L.V. (1997). Absorbtsionnyye kholodilnyye mashiny i teplovyye nasosy. Astrakhan: AGTU

20. Byikov, A.V. (1982). Kholodilnyye mashiny: Spravochnik. Moskva: Legkaya i pischevaya promyshlennost

21. Tseytlin, Yu.A., Abramova, T.G., Mogilevskiy, V.I., Roytman, V.F., Chernichenko, V.K. (1983). Proyektirovaniye i ekspluatatsiya shakhtnykh sistem konditsionirovaniya vozdukha. Moskva: Nedra

22. Tseitlin, Yu.A., Oksen, Yu.I., Roitman, V.F., Mogilevsky, V.I. (1985) Optimization of design of large refrigeration systems for deep mines. Transactions of the Institution of Mining and Metallurgy (Section A: Mining industry), 94, 217-218

23. Oksen, Yu.I., Semeshko, E.G. (1994) The effect of stochasticity of thermophysical properties and rock temperature on the distribution of cooling power of mine air coolers. Fiziko-tekhnicheskiye problemy razrabotki poleznykh iskopayemykh, 1, 87-91 